\title{
The relationship between grade 11 learners' procedural and conceptual knowledge of algebra
}

\author{
Munyaradzi Chirove, Ugorji Iheanachor Ogbonnaya \\ Department of Science, Mathematics \& Technology Education, University of Pretoria, South Africa \\ *Corresponding author: chirovem25@gmail.com
}

\begin{tabular}{|c|c|}
\hline ARTICLE INFO & ABSTRACT \\
\hline $\begin{array}{l}\text { Article history: } \\
\text { Received: } 6 \text { June } 2021 \\
\text { Revised: } 28 \text { August } 2021 \\
\text { Accepted: } 2 \text { September } 2021 \\
\text { Published online: } 28 \text { October } \\
2021 \\
\text { Published regularly: October } \\
2021\end{array}$ & $\begin{array}{l}\text { The acquisition of procedural and conceptual knowledge is imperative for } \\
\text { the development of problem solving skills in mathematics. However, } \\
\text { while there are mixed research findings on the relationship between the } \\
\text { two domains of knowledge in some branches of mathematics, the } \\
\text { relationship between learners' procedural and conceptual knowledge of } \\
\text { algebra has not been well explored. This research paper examined the } \\
\text { relationship between Grade } 11 \text { learners' procedural and conceptual } \\
\text { knowledge of algebra. Data for the study was collected using an algebra } \\
\text { test administered to } 181 \text { grade } 11 \text { learners in Gauteng province, South } \\
\text { Africa. Descriptive statistics and Pearson's correlation coefficient were } \\
\text { used to analyse the data in SPSS. The study revealed that the learners } \\
\text { have low levels of both procedural and conceptual knowledge of algebra. } \\
\text { However, they displayed better procedural knowledge than the }\end{array}$ \\
\hline $\begin{array}{l}\text { Keywords: } \\
\text { Algebra, conceptual } \\
\text { knowledge, procedural } \\
\text { knowledge, mathematics }\end{array}$ & $\begin{array}{l}\text { conceptual knowledge of algebra. In addition, a statistically significant } \\
\text { moderate positive linear relationship was found between the learners' } \\
\text { procedural and conceptual knowledge of algebra. }\end{array}$ \\
\hline
\end{tabular}

South Africa

(C) 2021 Universitas Muhammadiyah Surakarta

\section{Introduction}

Algebra is one of the branches of mathematics that challenge many learners because of the level of abstract thinking involved (Star, et al., 2015; Tularam \& Hulsman, 2013; Egodawatte, 2011). Success in algebra requires a learner to master various representations (e.g., symbols, equations, tables, and graphs) and reason logically. To facilitate a deep understanding of algebra, Star et al. (2015) advocate instruction that promotes the development of connections between procedures and their corresponding algebraic concepts. The task of linking procedural and conceptual mathematical knowledge is viewed by Kadijevich (2018) as a major challenge to teachers. The challenge to teachers could be even greater given that some studies (e.g., Chinnappan \& Forrester, 2014; Zakaria \& Zaini, 2009; Huang, Liu \& Lin, 2007) show that mathematics teachers' level of both procedural and conceptual knowledge in mathematics range from low to average. Besides, some studies show an absence of a significant linear relationship between teachers' procedural and conceptual knowledge in mathematics (e.g., Khashan, 2014). As such, procedural knowledge could be viewed as existing independent of conceptual knowledge within the teachers studied. 
In South Africa, one of the aims of the secondary school curriculum is to develop learners' problem solving skills. The curriculum advocates teaching methodologies that are not limited to "how" but incorporate problem types of "when" and "why". Secondary school learners are expected to be exposed to many opportunities that can develop their mathematical reasoning and creative skills in preparation for more sophisticated and abstract mathematics in tertiary education institutions. However, grade 12 learners' application of algebraic skills in final examinations was found to be poor in five successive years 2014 to 2019 (DBE, 2019). They were observed to perform poorly on questions that assessed understanding of concepts. Their poor performance was assumed to be caused by learning procedures and proofs without a good understanding of basic underlying concepts, thus leaving them ill-equipped to use their knowledge in later life.

The role of procedural and conceptual knowledge in the successful learning of mathematics at all levels of education cannot be overemphasised. Learners with deep conceptual and procedural knowledge of mathematics are more powerful in solving mathematical problems than those with shallow conceptual and procedural knowledge (Hurrel, 2021; Nahdi \& Jatsunda, 2020; Cummings, 2015; Schneider \& Sten, 2010). On this regard, Cummings ( $\underline{2015}$ ) posits that learners can effectively store and retrieve procedures to solve problems if they are connected to their underlying foundational concepts. Furthermore, a learner with conceptual knowledge of mathematics can easily reconstruct the mathematical knowledge or ideas because of knowledge of concepts that are related and connected (Mabilangan, Limjap \& Belecina, 2011). Conceptual knowledge also, enables learners to apply knowledge to solve a wide variety of mathematical problems. It enables them to evaluate the appropriateness of a procedure to a given problem situation (Ho, 2020; Crooks \& Alibali, 2014; Schneider, Rittle-Johnson, \& Star, 2011; Schneider \& Stern, 2010). As such, conceptual and procedural knowledge promote logical thinking, creativity, and procedural flexibility in problem solving.

Learners' difficulties in learning mathematics, misconceptions, and poor performance in mathematics seem to be connected to their levels of procedural and conceptual knowledge of mathematics. Studies by Syam (2019), Tularam and Hulsman (2013), Egodawatte (2011) and Figueras, Males and Otten (2008) reveal that learners with average levels of procedural and conceptual competence in algebra had a lot of misconceptions on variables, algebraic expressions, equations, and word problems. A study by Ndemo and Ndemo (2018) in Zimbabwe on secondary school learners' errors and misconceptions in learning algebra revealed a prevalence of both procedural and conceptual errors among the learners.

Despite the importance of procedural and conceptual knowledge of mathematics, literature on procedural and conceptual knowledge of mathematics reveals an ongoing debate on the definitions of these two terms. This problem is probably caused by the fact that conceptual knowledge is multi-faceted. Hence, researchers define it as they view it from different perspectives. The categorisation of conceptual knowledge by Crook and Alibali (2014) into six categories: Connection knowledge, general principle knowledge, knowledge of principles underlying procedures, category knowledge, symbol knowledge, and domain structure knowledge, explains the broadness of conceptual knowledge. Amid the lack of consensus among researchers on definitions of the terms, it was observed that researchers give their working definitions that guide their research work. There seems to be a challenge in separating the two types of knowledge and setting tasks that exclusively measure each of them (Kieran, 2013; Rittle-Johnson, Siegler \& Alibali, 2001; Haapasalo \& Kadijevich, 2000). 
Considering the multiple facets of conceptual knowledge, Crooks and Alibali (2014) suggest a common framework that divides conceptual knowledge into two types of principle knowledge: general and procedure-specific. General knowledge refers to knowledge of rules, definitions and aspects of domain structure. Procedure-specific knowledge refers to knowledge of why a specific procedure works on a specific problem, and why a procedure presented is correct or incorrect. In this study, the paper utilised Crooks and Alibali's (2014) conceptual framework. The use of a common framework on this issue could facilitate easy comparison and integration of the findings.

Studies on the relationship between procedural and conceptual knowledge of specific mathematics domains were done in several different geographical locations using participants of different age groups (see, for example, Tesfayi, Arefayne \& Micael, 2020; Donevska-Todorova, 2016; Khashan, 2014). However, these studies hardly yielded conclusive results on the issue. This was partly due to a failure to define explicitly the procedural and conceptual knowledge and, thereby, align all the measuring tasks to their definitions (Crooks \& Alibali, 2014). In addition, researchers use a wide range of different measures to quantify procedural and conceptual knowledge and measure different forms of conceptual knowledge (Crooks \& Alibali, 2014). This makes the integration of all the empirical findings within and across the specific mathematical domains a great challenge and, hence, making the research ground fertile for further study.

This current correlational study of secondary school learners' procedural and conceptual knowledge of algebra strived to shed light on the South African education system that would probably enlighten its constructive transformation. From the findings of this study, we will be able to know the relations between learners' conceptual and procedural knowledge of algebra. This might help teachers to know the knowledge domains to focus more attention on while teaching. The results of this study might also be of benefit to teacher training institutions in designing pre-service and in-service mathematics teacher education programmes. The study aimed to answer the following research questions:

1. What are the grade 11 learners' levels of conceptual and procedural knowledge of algebra?

2. Is there any statistically significant relationship between grade 11 learners' procedural and conceptual knowledge of algebra?

\section{Theoretical background}

Several definitions of procedural and conceptual knowledge are suggested by researchers in the literature (e.g., Khashan, 2014; Chinnappan \& Forrester, 2014; Star \& Stylianides, 2013). Haapasalo and Kadijevich (2000) view the distinction between procedural and conceptual knowledge as in form of terminology use only. They claim that there is a problem with setting acceptable tasks that can exclusively measure each type of knowledge. Similarly, Rittle-Johnson, Siegler and Alibali (2001) view procedural and conceptual knowledge as two types of knowledge that lie on a continuum. Hence, they cannot be completely separated. To be able to define them and distinguish one type of knowledge from the other, they suggest procedural and conceptual knowledge to be viewed as lying at the ends of this continuum. As such, Rittle-Johnson and Schneider (2012), Ghazali and Zakaria (2011) and Rittle-Johnson et al. (2001) simply define procedural knowledge as the knowledge of the steps one has to follow to resolve a problem. They view procedural knowledge as tied to specific types of problems that makes it hardly applied and adapted to novel problem situations.

Khashan (2014), Chinnappan and Forrester (2014), Star and Stylianides (2013), Hiebert ( $\underline{2013})$, Engelbrecht, Harding and Potgieter (2006), and Hiebert and Lefevre 
(1986) characterise procedural knowledge as composed of formulae, symbols, procedures, algorithms and rules that a learner applies skilfully to solve mathematical problems. Similarly, Hardin (2002) view procedural knowledge as composed of motor skills, cognitive skills and cognitive strategies (e.g., finding a pattern, modelling, working backward, systematic guessing and checking, logical reasoning, considering extreme cases). A learner with procedural knowledge knows how to apply procedures and can explain and justify how the answer is obtained, but he/she might fail to understand why a procedure or formula is applied in solving the problem (Zakaria \& Zaini, 2009).

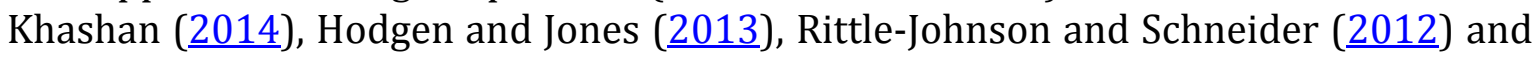
Rittle-Johnson et al. (2001) characterise conceptual knowledge as abstract knowledge that is composed of related concepts and principles. Conceptual knowledge of mathematics is viewed by Chinnappan and Forrester (2014) and Ghazali and Zakaria (2011) as involving a deep understanding of the foundational concepts that relate to algorithms used in mathematics. Conceptual knowledge is evident in the learner's ability to interpret and apply concepts correctly to a variety of problem situations and express concepts in different equivalent mathematical representations (Star \& Stylianides, 2013; Mabilangan et al., 2011; Engelbrecht et al., 2006; Star \& Seifert, 2006). Thus, conceptual knowledge enables a learner to interpret a problem situation correctly and, thereafter, select appropriate concepts and procedures to solve the problem. The interconnectedness of concepts improves effectiveness in solving a variety of mathematical problems because of the enhanced ability to see connections and apply the knowledge. According to Long (2005), procedural knowledge is identified as having a sequential nature while conceptual knowledge is identified by relationships between pieces of knowledge.

The distinction between procedural and conceptual knowledge is somehow complex. Procedural knowledge (knowing procedures, strategies, algorithms, and rules) is heavily nested in the knowledge of concepts. Long (2005) argues that algorithms could be conceived as representing some form of compressed conceptual knowledge. Procedures serve as a vehicle for accessing and acting on the conceptual knowledge, thereby revealing its existence (Hiebert \& Lefevre, 1986). Kieran (ㅁ13) describes the dichotomous distinction between procedures and concepts as false. The two constructs are inseparable in the sense that procedural knowledge is permeated with conceptual knowledge.

There seems to be a lack of consensus within the mathematics education community on definitions of conceptual and procedural knowledge. The differences in definitions of these concepts seem to arise from viewing them in two different perspectives: knowledge type and knowledge quality (Kieran, 2013; Star, 2005 2007; Rittle-Johnson \& Alibali, 1999; Hiebert \& Lefevre, 1986). For example, Hiebert and Lefevre (1986) conceive of conceptual and procedural knowledge as types of knowledge, while Egodawatte and Stoilescu (2015) view them as qualities of knowledge. Crooks and Alibali (2014) subdivides conceptual knowledge into two types: general knowledge of principles and knowledge of principles that underlie procedures. The general knowledge of principles involves knowledge of rules, definitions, symbols, and categories. Knowledge of principles underpinning procedures involves knowledge of why certain procedures work for certain problems. It involves knowledge of connections among steps in a procedure. Conceptual knowledge is characterised as deep-level understanding that is associated with the ability to understand, evaluate, critically judge, and flexibly apply knowledge to novel situations. On the other hand, procedural knowledge is viewed as superficial or surface-level knowledge that is associated with rote learning, reproduction, and inflexibility (De Jong \& Ferguson-Hestler, 1996). Viewers of conceptual and procedural knowledge as knowledge types focus on what a learner knows. As such, conceptual knowledge would be viewed as knowledge of 
concepts, principles, and definitions, while procedural knowledge would refer to knowledge of procedures and algorithms used in problem solving.

In the light of this discussion, the research paper views procedural knowledge as the ability to solve mathematical problems by the use of memorised procedures, strategies, algorithms, or formulae. All the definitions of conceptual knowledge seem to concur on the understanding of concepts that are richly connected and related. Conceptual knowledge is viewed as knowledge of mathematics that is constructed from interconnecting and relating various mathematical concepts and ideas. It is the conceptual knowledge that enables one to understand and explain how and why a certain mathematical procedure or formula is used and works in a given situation. Furthermore, the research paper viewed conceptual and procedural knowledge as types of knowledge. Subsequently, the questions in the test were classified as conceptual or procedural knowledge questions based on the depth of knowledge required to answer them.

\section{Relationship between procedural and conceptual knowledge of mathematics}

Some studies (e.g., Ghazali \& Zakaria, 2011; Huang, et al., 2007; Engelbrecht et al., 2006) revealed the presence of a positive linear relationship between procedural knowledge and conceptual knowledge. Ghazali and Zakaria (2011) studied Malaysian secondary school learners' procedural and conceptual understanding of mathematics and discovered a significant positive relationship between the two constructs. Similarly, Engelbrecht et al. (2006) studied 235 South African first-year applied mathematics learners' procedural and conceptual knowledge of calculus. They administered a multiplechoice test of 10 items of which 5 items were considered to be predominantly procedural and the other 5 items were predominantly conceptual. They analysed the data using scatter plots and Pearson's correlation coefficient. They discovered a moderate positive correlation between the two constructs. Some researchers contend that the development of procedural knowledge may lead to gains in conceptual knowledge of mathematics and vice versa. For instance, Rittle-Johnson and Alibali (1999) discovered a causal relationship between procedural and conceptual knowledge in the sense that conceptual instruction yielded an increased conceptual understanding and an ability to generate and transfer correct procedures. On the other hand, procedural instruction yielded an increased conceptual understanding and adoption of procedures that were taught.

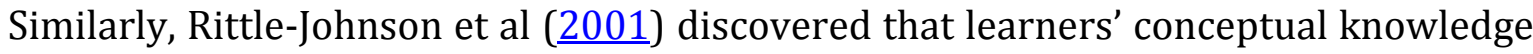
could predict their gains in procedural knowledge and vice versa. They concluded that the development of procedural knowledge and conceptual knowledge was iterative. A study conducted in Canada by Egodawatte and Stoilescu (2015) on grade 11 mathematics students' difficulties in applying conceptual, procedural skills, strategic competence, and algebraic thinking in solving routine (instructional) algebraic problems revealed that learners lack relational application and structural abilities when solving instructional problems. They discovered an overuse of procedures by learners that was coupled with an inability to evaluate their effectiveness. On the same note, Ai-Mutawah, Thomas, Mahmond and Fateel (2019) discovered a positive correlation between conceptual understanding and problem solving. A significant learner improvement on conceptual knowledge of mathematics could result in improvement of the learner's problem-solving proficiencies.

Some studies (e.g., Lenz \& Wittmann, 2021; Maulina, Zubainur \& Bahrun, 2020; Khashan, 2014; Forrester \& Chinnappan, 2010) focused on measuring learners' or preservice teachers' levels of procedural and conceptual knowledge of mathematics. Lenz and Wittmann (2021) discovered that grade 8 and 9 students in Germany had weaker procedural knowledge than conceptual knowledge of fractions. Khashan (2014) and

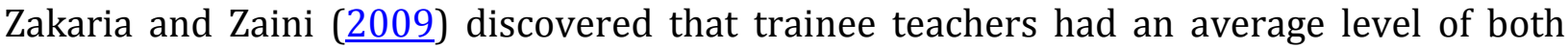


conceptual and procedural knowledge of rational numbers. Chinnappan and Forrester's (2014) and Huang et al's (2007) studies revealed that the pre-service teachers displayed a better procedural knowledge of fractions than conceptual knowledge.

A critical review of research studies on the relationship between secondary school learners' procedural and conceptual knowledge of specific mathematics domains by Crooks and Alibali (2014) highlights a lack of consistency among researchers on defining these constructs and on the kinds of tools used to measure them quantitatively. Some tools used by the researchers were discovered to be unaligned to the claimed theoretical definitions of the terms. As such, the findings discovered could hardly be integrated to give a concise conclusion. Thus, the relationship between secondary school learners' conceptual knowledge and procedural knowledge of mathematics remains elusive. This study is an attempt to shed more light on the subject. Hence, it examined the relationship between secondary school learners' procedural and conceptual knowledge of algebra.

\section{Research Methods}

This study made use of a descriptive correlational research design to determine, classify, and describe learners' levels of procedural knowledge and conceptual knowledge of algebra and the relationship between the two constructs. In South African secondary schools, algebra is taught from grade 8 to 12 on a content cumulative basis. The participants were expected to have acquired the procedural and conceptual knowledge of algebra covered in grades 8, 9 and 10. The participants consisted of all 181 grade 11 mathematics learners at a randomly selected secondary school in Tshwane North District, Gauteng Province, South Africa. Data was collected using an algebra test of 10 questions based on the following topics: algebraic expressions (simplifying and factorising), linear equations, linear inequalities, and functions. The questions of the algebra test could be classified into predominantly procedural knowledge questions (1, 2, 4, 8 \& 9) and predominantly conceptual knowledge questions $(3,5,6,7 \& 10)$. Though some elements of procedural knowledge and conceptual knowledge co-exist in each question, the questions were categorised as procedural knowledge or conceptual knowledge questions based on the dominant knowledge type measured by each question. The questions used for evaluating the learners' procedural knowledge and the explanation of how the knowledge was measured are shown in Table 1.

Table 1

Predominant procedural knowledge questions

\begin{tabular}{|c|c|}
\hline Question & Procedural knowledge as tested \\
\hline $\begin{array}{l}\text { 1. Calculate the value of } x \text { in } \\
\qquad 2 x-1=5-x\end{array}$ & $\begin{array}{l}\text { Procedures of solving a simple linear equation: - collecting like terms } \\
\text { and making the named variable the subject of the formula. }\end{array}$ \\
\hline $\begin{array}{l}\text { 2. Factorise completely } \\
\qquad a-b-a x+b x\end{array}$ & $\begin{array}{l}\text { Steps taken in factorising the algebraic expressions by grouping } \\
\text { terms in pairs. }\end{array}$ \\
\hline $\begin{array}{l}\text { 4. Calculate the value of } x \text { in the } \\
\text { inequality }\end{array}$ & $\begin{array}{l}\text { Sequential steps taken in solving the linear inequality: removing the } \\
\text { brackets, collecting like terms, and making the variable the subject of }\end{array}$ \\
\hline $2 x-1 \geq(2 x+1) 3$ & \\
\hline $\begin{array}{l}\text { 8. Solve the equations } \\
\text { simultaneously }\end{array}$ & $\begin{array}{l}\text { Methods and sequential steps taken to solve the linear simultaneous } \\
\text { equations. Elimination method: Eliminating one of the variables by }\end{array}$ \\
\hline$x+2 y=3$ and $4 x+5 y=$ & $\begin{array}{l}\text { adding or subtracting the two equations, and solving the equation in } \\
\text { one unknown. Substitution method: Making one of the variables the } \\
\text { subject of the equation, substitution into the second equation, and } \\
\text { solving the equation in one unknown. }\end{array}$ \\
\hline $\begin{array}{l}\text { 9. If } \frac{x+a}{x-b}=2, \text { determine } x \text { in terms } \\
\text { of } a \text { and } b\end{array}$ & $\begin{array}{l}\text { Sequential steps taken to change the subject of the formula: } \\
\text { Eliminating fractions, collecting terms in } x \text {, factorisation, and, } \\
\text { eventually, making } x \text { the subject of the formula }\end{array}$ \\
\hline
\end{tabular}


The questions used for evaluating the learners' conceptual knowledge and the explanation of the description of how the knowledge was measured are shown in Table 2. This algebraic test covered a wide range of algebraic concepts, thereby making it suitable for exploration for both the learners' procedural and conceptual knowledge of algebra (Donevska-Todorova, 2016). By utilising multiple tasks to assess both procedural and conceptual knowledge, we could tap both explicit and implicit procedural and/or conceptual knowledge of algebra. The algebra test was validated by three experienced secondary school mathematics teachers. The Cronbach reliability coefficient computed using SPSS, for the algebra test was $\alpha=0.788$, which was good enough for it to be considered as reliable. Learners' mean scores on procedural and conceptual items were computed and used to assess their levels of procedural and conceptual knowledge of Algebra and compute the Pearson's correlation coefficient to assess the form and strength of the relationship between the constructs.

Table 2

Predominant conceptual knowledge items

\begin{tabular}{lll}
\hline Question & & Conceptual knowledge tested \\
\hline 3. & $-2<x \leq 3$ & $\begin{array}{l}\text { Representing the solution of an inequality on a } \\
\text { number line graph. Given a wrong graphical } \\
\text { representation of a solution, identify and correct the } \\
\text { error made providing reasons for the corrections } \\
\text { done. }\end{array}$
\end{tabular}

Given that the number line graph that represents the solution $-2<x \leq 3$ is not correct, complete the statement below by circling -2 or 3 and give reason(s) for your answer. The circle at -2 or 3 should be shaded because

5. a). Which of the following statements is NOT TRUE about the equation $y=3-2 x$ ?

(Circle the correct answer)

A. $y$ is a function of $x$.

B. The value of $y$ depends on the value of $x$.

C. It shows that as $x$ increases, $y$ decreases.

D. It shows that as $x$ increases, $y$ increases.

5 (b). Circle the correct answer (linear/not Linear) BELOW and give reasons for your answer.

The relationship between $x$ and $y$ is linear/not linear because

6.

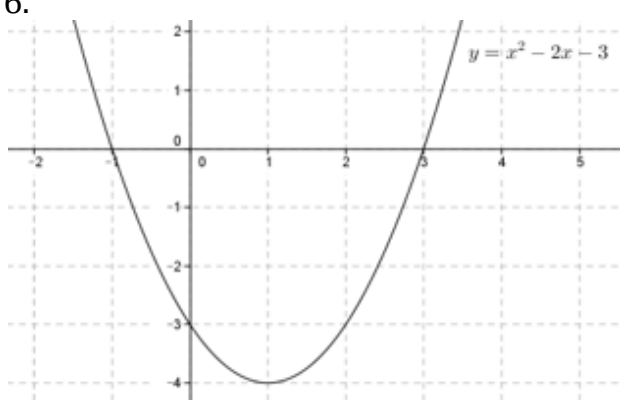

The roots of the equation $x^{2}-2 x-3=0$ are _ or _ because
Concept of a linear function: Selecting false statements about the given linear function. Justifying why the relationship between the variables was linear or not linear.

Concept of zeros of a quadratic function. Using the given graph to identify the roots of the given equation and justify why they selected the values. 
Table 2 (Continued)

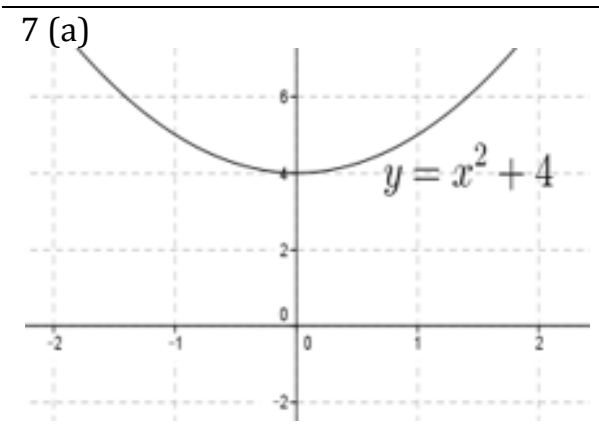

Circle the correct answer (real/non-real) BELOW and give reason(s) for your answer. The equation $x^{2}+4=0$ has real/non-real Roots because

7(b). Circle the correct answer (minimum/maximum) and complete the statement giving reason(s) for your answer.

$y=x^{2}+4$ has a minimum / maximum value equal to

_because

10(a). A girl's age is $x$ years and her father is 4 times as old. Find the father's age in $y$ years' time. (Circle the correct answer)
A. $4 x y$
B. $4 y+x$
C. $4 x+y$
D. $4 x-y$

10 (b). The width of a classroom is 4 meters less than the length. Its area is $45 \mathrm{~m}^{2}$. Let the width $=w$ meters and the length $=l$ meters long.
Concepts of real and non-real solutions to a quadratic equation. Using the given graph to state if the quadratic equation given has real or non-real roots with justification. Relating the nature of roots to graphical representations. Identifying the minimum or maximum value of the function given with reasons.

Relationship between or among quantities: Formulating algebraic expressions or equations from the word statements given (identifying and writing down the relationship that exists between or among quantities).

\section{Scoring the algebra test}

To facilitate scoring of the learners' responses to the test questions, marking rubrics that scored each question a maximum of 4 points and a minimum of zero points were used (see Tables $3 \& 4$ ). As a result, the whole test was scored out of 40 points. The rubric in Table 3 was used to assess the learners' procedural knowledge while the rubric in Table 4 was used to assess their conceptual knowledge.

Table 3

Marking rubric for algebra test: Procedural Knowledge

Indicators of procedural knowledge Code

Using appropriate symbols, formulae and procedures efficiently

Executing all the steps correctly.

Not precise in using mathematical symbols, formulae and procedures.

Executing more than half, but not all, of the steps on solving the problem correctly.

Executing correctly at most half of the relevant steps on solving the problem.

Starts solving the problem appropriately but later diverts to applying incorrect procedures.

Presenting only one correct step on solving the problem.

Applying wrong procedures to solve the problem.

Presenting an answer only without showing the procedures used

Leaving the answer sheet blank.

0

Copying parts of or the whole problem without attempting to solve it.

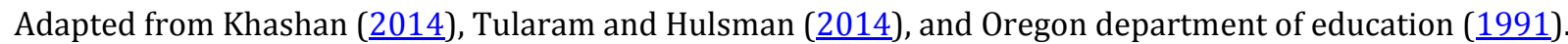


The rubrics were developed by modifying the rubrics suggested by Tularam and Hulsman (2014), Khashan (2014), and the Oregon Department of Education (1991) to suit the current study. The Oregon Mathematics problem solving rubrics were composed of two separate sets of rubrics: one for assessing and scoring learners' procedural knowledge and the other one for conceptual knowledge of grades 5 to 11 learners. Similarly, Tularam and Hulsman (2014) developed two separate rubric sets for assessing procedural knowledge and conceptual knowledge of first-year applied mathematics university students in algebra (e.g., linear and quadratic functions, limits). They examined learners' written scripts to gain insight into the reasons for failure of most mathematics learners who pursued applied mathematics. Unlike Tularam and Hulsman (2014) and the Oregon Department of Education (1991), Khashan (2014) suggested a generic marking rubric that could be applied to assess and score primary school teachers' procedural knowledge and the conceptual knowledge of rational numbers. A similar rubric was historically designed and used by Faulkenberry ( $\underline{2003}$ ) for assessing secondary mathematics pre-service teachers' conceptions of rational numbers. Though they developed a test of 34 items of which half of the items were designed to measure procedural knowledge while the other half was for measuring conceptual knowledge, all items were assessed and scored using one generic rubric. However, in this study, using Khashan's (2014) rubric in conjunction with Tularam and Hulsman's (2014) and Oregon department of education's (1991) rubrics, the researchers separated rubric items predominantly meant to assess each type of knowledge and presented a rubric for scoring procedural knowledge and another rubric for assessing conceptual knowledge.

Table 4

Marking rubric for algebra test: Conceptual Knowledge

\begin{tabular}{lc}
\hline Indicators of conceptual knowledge & Code \\
\hline Making use of all the relevant information in the problem situation to solve the problem. & 4 \\
Connecting the given information and presents correct mathematical expressions or statements. & \\
Extending or generalising the solution or problem. & \\
Verifying, explaining or justifying his/her solution satisfactorily using appropriate procedures. \\
Presenting alternative solutions to the problem (e.g., graphs) to illustrate some relationships among \\
conceptual constructs.
\end{tabular}

Using more than half, but not all, of the relevant information to solve the problem.

Translating the problem situation into mathematical expressions or statements but makes few errors on using the statements to solve the problem.

Partially able to make connections between/among concepts.

Verifying the solution is partially correct.

Identifying a correct procedure but explaining or justifying his/her solution unsatisfactorily.

Using at most half of the relevant information to solve the problem.

Stating the concepts involved but failing to connect them.

Identifying a correct procedure but failing to verify, explain or justify his/her solution.

Writing down the important information in the problem situation but failing to use it to solve the problem

Translating the problem into inappropriate mathematical concepts.

Applying an incorrect procedure to verify the solution.

Leaving the answer sheet blank.

Presenting some information that is not linked or related to the problem situation.

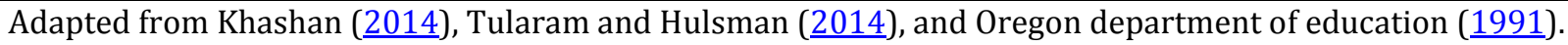


Analysis of the algebra test

Descriptive statistics, namely percentage, mean, and standard deviation, were used to describe learners' procedural and conceptual knowledge of algebra. Their responses to each question were analysed and excerpts of their written work were used as concrete examples. The research paper made use of the percentage scores in procedural and conceptual knowledge to determine and categorise the learners' levels of procedural and conceptual knowledge in algebra (see Table 5). As such, four randomly selected answers sheets; composed of one answer sheet selected from each of the categories: 'very low' achievers (0\%-29\%), 'low' achievers (30\%-44\%), 'average' achievers (45\%-59\%), and 'high' achievers (60\%-100\%), were used as examples of learners' written work. The mean and standard deviation were calculated to determine each learner's average score in procedural knowledge, conceptual knowledge, and the whole algebra test and the deviations of the raw scores from the mean score. The researchers calculated Pearson's correlation coefficient between their mean scores in procedural and conceptual knowledge test to determine the relationship between the two variables.

Table 5

Criteria used to classify learners' levels of PK and CK

\begin{tabular}{ccc}
\hline Code & Percentage score & Level of PK/CK \\
\hline 1 & $0-29$ & Very low \\
2 & $30-44$ & Low \\
3 & $45-59$ & Average \\
4 & $60-100$ & High
\end{tabular}

Adapted from Khashan (2014) and Zakaria and Zaini (2009).

PK- Procedural Knowledge; CK- Conceptual Knowledge

\section{Results and Discussion}

\section{Procedural knowledge of algebra}

An analysis of their answers to the PK questions (Q1, Q2, Q4, Q8 \& Q9) revealed that $57.5 \%$ of them achieved high in question 1 . They were able to group like terms, simplify and present a step-by-step solution to the problem (see Table 6).

Table 6

Percentage number of learners and their scores per question

\begin{tabular}{|c|c|c|c|c|c|c|c|}
\hline & \multirow[b]{2}{*}{ Question } & \multicolumn{5}{|c|}{ Score } & \multirow[b]{2}{*}{ Total } \\
\hline & & 0 & 1 & 2 & 3 & 4 & \\
\hline \multirow{10}{*}{ 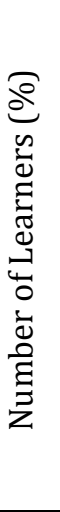 } & Q1 & 28.2 & 5.5 & 4.4 & 4.4 & 57.5 & 100 \\
\hline & Q2 & 75.1 & 10.5 & 2.2 & 5.0 & 7.2 & 100 \\
\hline & Q3 & 71.8 & 4.4 & 13.3 & 6.6 & 3.9 & 100 \\
\hline & Q4 & 38.1 & 10.5 & 13.8 & 24.9 & 12.7 & 100 \\
\hline & Q5 & 30.4 & 42 & 13.3 & 11.6 & 2.8 & 100 \\
\hline & Q6 & 73.5 & 13.3 & 8.8 & 1.1 & 3.3 & 100 \\
\hline & Q7 & 35.9 & 45.3 & 18.2 & 0.6 & 0.0 & 100 \\
\hline & Q8 & 49.7 & 9.9 & 3.9 & 7.7 & 28.7 & 100 \\
\hline & Q9 & 74.6 & 2.2 & 8.8 & 6.6 & 7.7 & 100 \\
\hline & Q10 & 61.9 & 32 & 1.7 & 1.7 & 2.8 & 100 \\
\hline
\end{tabular}

In addition, $14.4 \%$ of them scored $50 \%$ and above in Q2. On average they scored 0.59 out of 4 and standard deviation of 1.21 in Q2 (see Table 7). 
Table 7

Learners' mean scores and standard deviation on each question

\begin{tabular}{ccccccccccc}
\hline Question & 1 & 2 & 3 & 4 & 5 & 6 & 7 & 8 & 9 & 10 \\
\hline Mean & 2.57 & 0.59 & 0.66 & 1.64 & 1.14 & 0.48 & 0.83 & 1.56 & 0.71 & 0.51 \\
Std Dev. & 1.79 & 1.21 & 1.17 & 1.51 & 1.07 & 0.95 & 0.73 & 1.77 & 1.31 & 0.85 \\
\hline
\end{tabular}

The majority of them (66.3\%) scored $50 \%$ and above in question 1 . However, $28.2 \%$ of them could not apply any correct procedure in solving question 1 . They scored a mean value of 2.57 out of 4 with a standard deviation of 1.79 in question 1 . The majority of them $(75.1 \%)$ could not apply any correct procedure to solve Q2. Only $7.2 \%$ of them were able to identify, group terms with a common factor, factorise completely and present a step-bystep solution (e.g., see Figure 1).

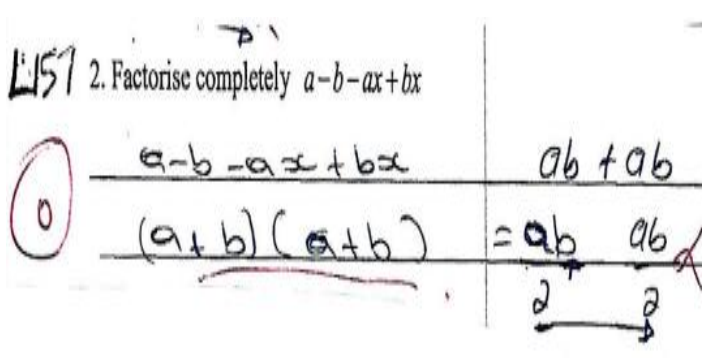

(a)



(b)

Figure 1: Example of typical learners' responses to Q2: (a) low achiever, (b) high achiever.

The percentage of them who scored high in Q4 was $12.7 \%$. They were able to group like terms, simplify the expressions and, ultimately, give the correct solution to the linear inequality problem. The percentage of them who scored at least $50 \%$ in Q4 was 51.4. A large number of them (38.1\%) were not able to execute any correct procedure to solve Q4. Their average score was 1.64 out of 4 with a standard deviation of 1.51 in Q4. The percentage of them who scored high in Q8 was 28.7. They were able to express one of the variables as the subject of the formula, do correct substitution and simplification. The percentage of them who scored at least 50\% in Q8 was 40.3. Nearly 50\% of them could not apply any correct procedure to solve Q8 (e.g., see Figure 2). They scored an average of 1.56 with a standard deviation of 1.77 in Q8. The majority of them (74.6\%) were not able to solve Q9. They could not determine the correct lowest common denominator (LCD) between the given two denominators and, or remove brackets and collect like terms. Only $7.7 \%$ of them were able to clear the fractions by multiplying both sides of the equation by the LCD, remove brackets, collect like terms, simplify and make $x$ the subject of the formula. A very small number of them (23.1\%) scored at least 50\% in Q9. Their average score and standard deviation in Q9 were 0.71 out of 4 and 1.31 , respectively.

A moderate number of them (42.5\%) scored less than 30\% in PK test and their level of PK in algebra was classified as 'Very low'. A small number of them (18.2\%) scored between 30\% and 44\%, inclusively, in PK test and their level in PK was classified as 'Low'. Only $11 \%$ of them scored between $45 \%$ and 59\%, inclusively, in PK test and their level in PK was classified as 'Average'. The 'high' achievers (28\% of them) scored $60 \%$ and above in the PK test (see Table 8). 


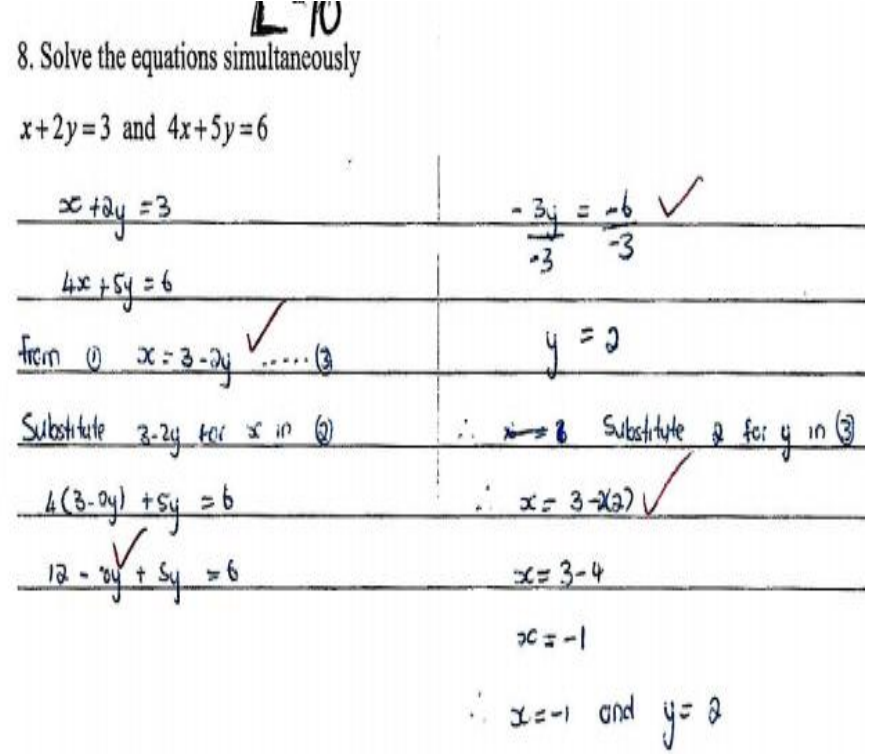

(a)
8. Solve the equations simultaneously $L 157$

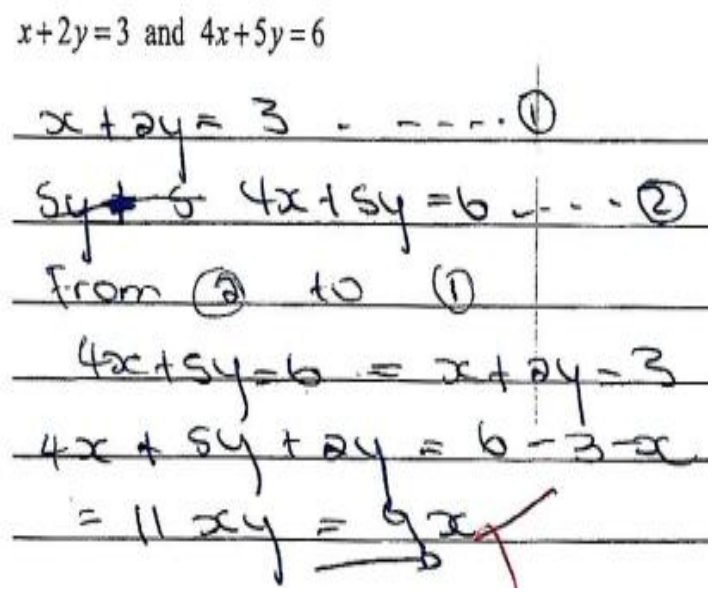

Figure 2: Example of typical learners' responses to Q8: (a) high achiever, (b) low achiever

Table 8

Number of learners in each level of PK in algebra

\begin{tabular}{llcccc}
\hline & & & & Cumulative \\
Valid & Very low & 77 & 42.5 & 42.5 & 42.5 \\
& Low & 33 & 18.2 & 18.2 & 60.8 \\
& Average & 20 & 11.0 & 11.0 & 71.8 \\
& High & 51 & 28.2 & 28.2 & 100.0 \\
& Total & 181 & 100.0 & 100.0 & \\
\hline
\end{tabular}

Their overall mean score in PK was 35.30 out of 100 with a standard deviation of 29.40. As such, their level of procedural knowledge of algebra was classified as 'Low' (see Tables 5 \& 9).

Table 9

Summary statistics of learners' scores in the test

\begin{tabular}{|c|c|c|c|c|c|}
\hline & $\mathrm{N}$ & Minimum & Maximum & Mean & $\begin{array}{r}\text { Std. } \\
\text { Deviation }\end{array}$ \\
\hline $\begin{array}{l}\text { Conceptual Knowledge } \\
\text { Percentage score }\end{array}$ & 181 & 0 & 85 & 18.15 & 15.084 \\
\hline $\begin{array}{l}\text { Procedural Knowledge } \\
\text { Percentage score }\end{array}$ & 181 & 0 & 100 & 35.30 & 29.397 \\
\hline $\begin{array}{l}\text { Algebra Test Percentage } \\
\text { score }\end{array}$ & 181 & 0 & 90 & 26.73 & 19.394 \\
\hline Valid N (listwise) & 181 & & & & \\
\hline
\end{tabular}

\section{Conceptual knowledge of algebra}

An analysis of their responses to CK items (Q3, Q5, Q6, Q7 \& Q10) revealed that 3.9\% of them achieved high in Q3 (see Table 6). They demonstrated an understanding of the concept of the solution set of an inequality. Given an incomplete linear inequality graph, they could identify the corrections to be done to it and justify their responses. The percentage of them who scored at least $50 \%$ in Q3 was $23.8 \%$. The majority of them (71.8\%) presented an incorrect response to the problem. They could not identify the correct point to be shaded and explain satisfactorily why the point should be shaded. They 
scored an average of 0.66 out of 4 with a standard deviation of 1.77 in Q3 (see Table 7). The majority of them (72.4\%) scored below 50\% in Q5. Out of these learners who scored below $50 \%, 30.4 \%$ of them identified an incorrect relation and $42.0 \%$ of them identified an incorrect relation/trend and a correct type of the relationship between the variables and gave an unsatisfactory justification of their response. Only $2.8 \%$ of them were able to score high in Q5. Their average score in Q5 was 1.14 with a standard deviation of 1.07.

In responding to Q6, the majority of them (73.5\%) could not demonstrate an understanding of the concept of a root of a quadratic equation. They could not identify the roots from the given graph. Only $4.4 \%$ of them could identify the two correct roots of the quadratic equation from the graph, and $3.3 \%$ of them could satisfactorily explain why the two values were roots to the given equation. They scored an average of 0.48 out of 4 with a standard deviation of 0.95 in Q6. The percentage of them who scored below $50 \%$ in Q7 was $81.2 \%$. Out of these $81.2 \%$ learners, $35.9 \%$ of them could not state the nature of the roots or the minimum/maximum value of the given function with satisfactory explanations (e.g., see Figure 3).

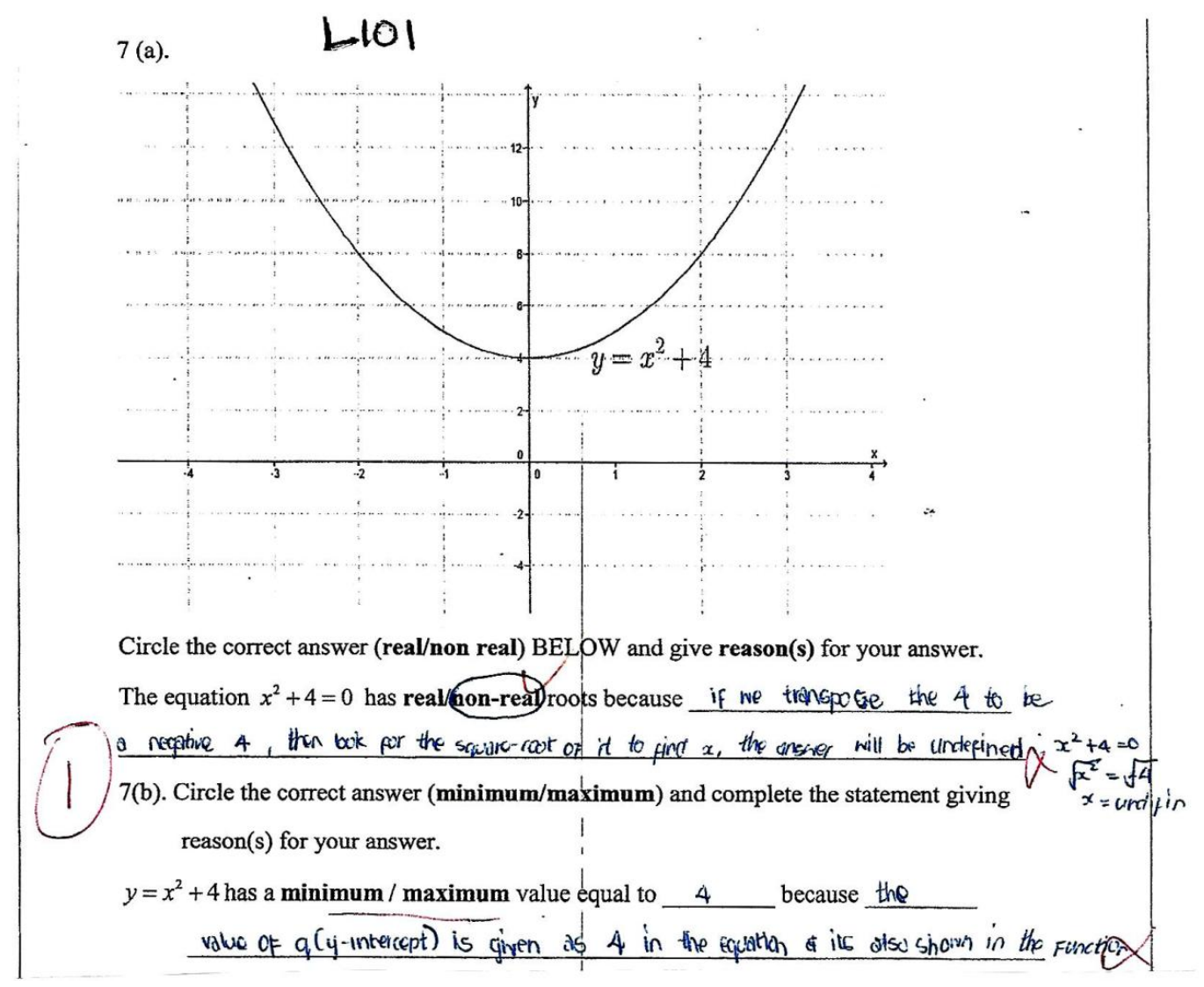

Figure 3. An example of a very low achiever's response to Q7

None of them scored high in Q7. Their average score in Q7 was 0.83 with a standard deviation of 0.73. A small number of them (2.8\%) scored high in Q10 (e.g., see Figure 4). The majority of them (93.9\%) scored below 50\% in Q10. Out of these $93.9 \%, 61.9 \%$ of them could not represent the word statements with correct algebraic expressions (e.g., see Figure 5). Their average score in Q10 was 0.51 with a standard deviation of 0.85 . 


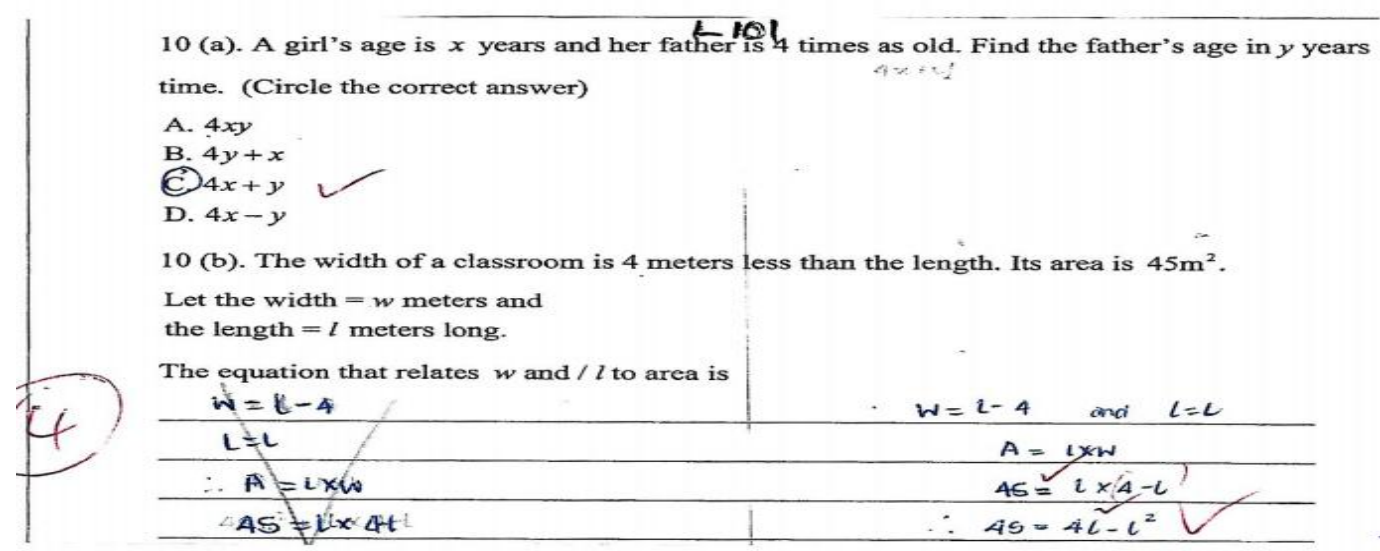

Figure 4: An example of a high achiever's response to Q10

10 (a). A girl's age is $x$ years and her father is $\underline{4}$ times as old. Find the father's age in $y$ years time. (Circle the correct answer)

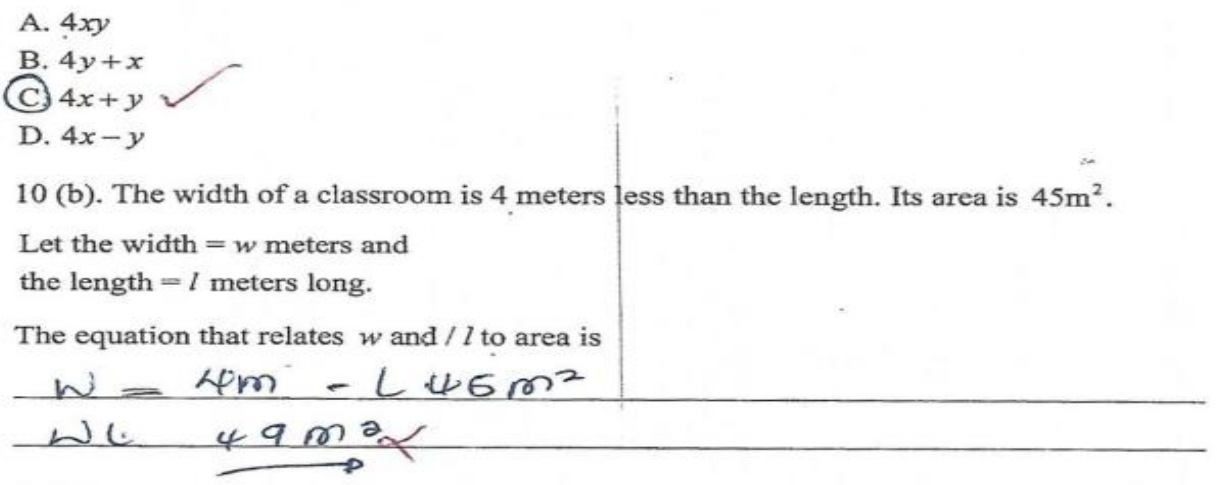

Figure 5: An example a very low achiever's response to Q10

The majority of them (81.2\%) scored less than 30\% in CK test and their level of CK in algebra was classified as 'Very low'. Only $12.2 \%$ of them scored between $30 \%$ and $44 \%$, inclusively, in CK test, and their level in CK was classified as 'Low'. Few learners (30.3\%) scored between 45\% and 59\%, inclusively, in CK test, and their level in CK was classified as 'Average'. A small number of them (3.3\%) scored at least 60\% in CK test and their level in CK was classified as 'High' (see Table 10). Their overall mean score in CK was 18.15 out of 100 with a standard deviation of 15.08. As such, their level of conceptual knowledge of algebra was classified as 'Very low' (see Tables $5 \& 9$ ). Overall, their mean score in the algebra test was 26.73 with a standard deviation of 19.39 (see Table 9). Their level of overall knowledge of algebra could be classified as 'Very low'.

Table 10

Number of learners in each level of CK in algebra

\begin{tabular}{|c|c|c|c|c|c|}
\hline \multicolumn{6}{|c|}{ Levels of Conceptual Knowledge } \\
\hline & & Frequency & Percent & Valid Percent & $\begin{array}{l}\text { Cumulative } \\
\text { Percent }\end{array}$ \\
\hline \multirow[t]{5}{*}{ Valid } & Very low & 147 & 81.2 & 81.2 & 81.2 \\
\hline & Low & 22 & 12.2 & 12.2 & 93.4 \\
\hline & Average & 6 & 3.3 & 3.3 & 96.7 \\
\hline & High & 6 & 3.3 & 3.3 & 100.0 \\
\hline & Total & 181 & 100.0 & 100.0 & \\
\hline
\end{tabular}


The relationship between procedural knowledge and conceptual knowledge in algebra

A moderate positive linear relationship ( $r=0.465 ; \alpha=0.01$ ( 2 tailed)) between learners' procedural knowledge mean scores and their conceptual knowledge mean scores in algebra was found (see Table 11). This is similar to the results of the Ghazali and Zakaria (2011) and Huang et al. (2007) who found a significant positive linear relationship between learners' procedural knowledge and conceptual knowledge of mathematics. The presence of a positive linear relationship between the two types of knowledge might mean that some positive gains in procedural knowledge of algebra could result in some positive gains in conceptual knowledge of algebra and vice versa. However, the finding does not agree with Khashan's (2014) finding that revealed no significant linear relationship between the two types of knowledge.

Table 11

Pearson's correlation coefficient, procedural knowledge versus conceptual knowledge

\begin{tabular}{|c|c|c|c|}
\hline & & $\begin{array}{l}\text { Procedural } \\
\text { Knowledge Mean } \\
\text { Score }\end{array}$ & $\begin{array}{l}\text { Conceptual Knowledge } \\
\text { Mean Score }\end{array}$ \\
\hline \multirow[t]{3}{*}{ Procedural Knowledge Mean Score } & Pearson Correlation & 1 & $.465^{* *}$ \\
\hline & Sig. (2-tailed) & & .000 \\
\hline & $\mathrm{N}$ & 181 & 181 \\
\hline \multirow[t]{3}{*}{ Conceptual Knowledge Mean Score } & Pearson Correlation & $.465^{* *}$ & 1 \\
\hline & Sig. (2-tailed) & .000 & \\
\hline & $\mathrm{N}$ & 181 & 181 \\
\hline
\end{tabular}

**. Correlation is significant at the 0.01 level (2-tailed).

The coefficient of determination, $R^{2}=0.2162$, means that $21.62 \%$ of the gains in procedural knowledge of algebra could be explained by the gains in conceptual knowledge of algebra and vice versa. It supports Rittle-Johnson and Alibali's (1999) finding that discovered a causal relationship between procedural and conceptual knowledge. It is, also, in line with Rittle-Johnson et al's (2001) findings that learners' conceptual knowledge could predict their gain in procedural knowledge and vice versa.

\section{Discussion}

The learners revealed varied levels of both procedural knowledge and conceptual knowledge of algebra in responding to specific problems. Most of them had a high mastery of procedures in solving linear equations. They had average levels of procedural knowledge in solving linear inequalities and solving simultaneous linear equations. They revealed low levels of procedural knowledge in factorising four algebraic terms and changing the subject of the formula of fractional algebraic equations. On average, they had low levels of procedural knowledge of algebra.

The majority of them had low levels of conceptual knowledge of different representations of a solution to an inequality. They also revealed a shallow conceptual knowledge of the linear function and the relationship that exist between the two variables in a linear function. Furthermore, low levels of conceptual knowledge of algebra were observed on roots of a quadratic equation, the graphical solution to a quadratic equation, nature of roots, maximum and minimum values of quadratic functions, and different representations of mathematical statements. They could not locate the roots on a given graph and explain why the values are roots to the equation. The possible cause of this might be teachers who do not expose them to different ways of solving quadratic equations, e.g., the graphical method. Their failure to explain why the values are roots to an 
equation might be attributed to heavy dependence on routine procedures or algorithms to solve quadratic equations without deep underlying conceptual knowledge. Failure to transform word statements to algebraic statements might be due to failure to understand the problem situation and lack of conceptual knowledge required to link the different concepts in the problem.

Their conceptual knowledge mean score was lower than their procedural knowledge mean score in algebra. This could mean that they displayed a better procedural knowledge of algebra than conceptual knowledge. It agrees with Ho (2020), Chinnappan and Forrester's (2014), and Huang et al's (2007) findings that learners displayed a better procedural than conceptual knowledge of fractions. However, it is contrary to Lenz and Wittmann's (2021) discovery that students were weaker on procedural than conceptual knowledge of fractions. It might reflect that they spent most of their time on understanding mathematical procedures than acquiring a deep conceptual understanding of mathematics. It might be attributed to teachers' conventional teaching approaches that promote the acquisition of procedural knowledge more than the conceptual knowledge of mathematics. They had low levels of both procedural and conceptual knowledge of algebra. It is inconsistent with Tularam and Hulsman's (2013) and Egodawatte's (2011) findings that discovered that the learners in their studies had average levels of both procedural and conceptual knowledge of algebra.

They had a very low mean score in the overall knowledge of algebra that could be attributed to the low-level procedural and conceptual knowledge of algebra. Learners with low levels of both procedural and conceptual knowledge were observed by Tularam and Hulsman ( $\underline{2013}$ ) to have a lot of misconceptions on variables, algebraic expressions, equations, and word problems. On a similar note, Ho (2020) discovered that students with higher procedural knowledge than conceptual knowledge had a very low ability to integrate the two types of knowledge.

The positive nature of the linear relationship between their procedural and conceptual knowledge of algebra could mean that the employment of teaching and learning methodologies that promote the development of, for instance, conceptual knowledge could result in positive gains of the procedural knowledge, and vice-versa. The moderate strength of the relationship could also mean that some gains in conceptual knowledge of Algebra could result in some relatively significant moderate gains in procedural knowledge, and vice-versa. It is in agreement with Tesfayi et al's ( $\underline{2020})$, Ghazali and

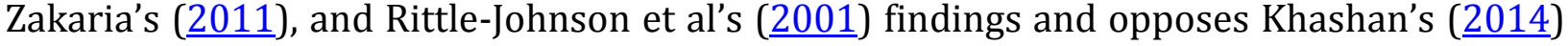
findings that discovered a non-significant weak positive linear relationship between the constructs.

\section{Conclusion}

This study examined the relationship between Grade 11 learners' procedural and conceptual knowledge of algebra. It found that they have low levels of procedural and conceptual knowledge of algebra. They displayed better procedural than the conceptual knowledge of algebra. There exists a moderate positive linear relationship between their procedural and conceptual knowledge of algebra. The existence of some significant positive linear relationship between the two types of knowledge could mean that efforts exerted on improving one might lead to improvement on the other. However, the results of this study might apply only to the school under study. In the light of the findings of this study, it is recommended that teachers should teach algebra to learners focusing on the development of conceptual knowledge. A deep understanding of procedures should be facilitated by understanding their underlying foundational concepts. Teachers of mathematics need to be 
made aware of some applicable teaching and learning strategies that promote conceptual knowledge of mathematics through in-service training workshops. Similar studies on the relationship between secondary school learners' procedural and conceptual knowledge of algebra should be conducted at different settings with large random samples of participants to shed more light on this problem and to obtain generalisable results. It is recommended to conduct similar studies to determine experienced secondary school teachers' levels of both procedural and conceptual knowledge of mathematics. It is assumed that teachers' level of procedural and conceptual knowledge in mathematics might relate to their learners' levels of procedural and conceptual knowledge in mathematics.

\section{Acknowledgments}

We express our sincere gratitude, appreciation and indebtedness to the school principal, mathematics teachers, heads of mathematics departments and learners for their invaluable contributions to the success of the paper. Additionally, special thanks go to Freddia Chirove for assistance in paper proofreading and language editing.

\section{Bibliography}

Ai-Muatawah, M., Thomas, R., Eid, A., Mahmond, E. Y., \& Fateel, M. J. (2019). Conceptual understanding, procedural knowledge and problem-solving skills in mathematics: High school graduates work analysis and standpoints. International journal of $\begin{array}{llll}\text { education } \quad \text { and } & \text { practice, } & \text { 258-273. }\end{array}$ https://doi.org/10.18488/journal.61.2019.73.258.273

Chinnappan, M., \& Forrester, T. (2014). Generating procedural and conceptual knowledge of fractions by preservice teachers. Mathematics education research journal, 26(4), 871-896.

Crooks, N. M., \& Alibali, M. W. (2014). Defining and measuring conceptual knowledge in mathematics. Developmental review, 34, 344-377.

Cummings, K. (2015). How does tutoring to develop conceptual understanding impact student understanding? In BSU Honors Program Theses and Projects, Item 96. Bridgewater: Bridgewater State University. Retrieved from http://vc.bridgewedu/honors proj/96

De Jong, T., \& Ferguson-Hestler, M. (1996). Types and qualities of knowledge. Educational psychologist, 31(2), 105-113. https://doi.org10.1207/s15326985ep3102 2

Department of Basic Education. (2019). Report on the 2019 national senior certificate diagnostic report, part 1. Gauteng, South Africa: Department of basic education.

Donevska-Todorova, A. (2016). Procedural and conceptual understanding in undergraduate linear algebra. First conference of international network for didactic research in university mathematics. Montpeller. Retrieved from https://hal.archivesouvertertes.fr/hal-01337932

Egodawatte, G. (2011). Secondary school students' misconceptions in Algebra. Unpublished doctoral thesis. Toronto: University of Toronto.

Egodawatte, G., \& Stoilescu, D. (2015). Grade 11 students' interconnected use of conceptual knowledge, procedural skills, and strategic competences in algebra: A mixed method study of error analysis. European journal of science and mathematics education, 3(3), 289-305. https://doi.org/10.30935/scimath/9438

Engelbrecht, J., Harding, A., \& Potgieter, M. (2006). Undergraduate students' performance and confidence in procedural and conceptual mathematics. International journal of 
mathematical education in science and technology, 36(7), 701-712. https://doi.org/10.1080/00207390500271107

Faulkenberry, E. (2003). Secondary mathematics preservice teachers' conceptions of rational numbers. Unpublished doctoral dissertation. Oklahoma: Oklahoma State University.

Figueras, H., Males, L., \& Otten, S. (2008). Algebra students' simplification of rational expressions. Retrieved February 27, 2016, from www.msu.edu

Forrester, P. A., \& Chinnappan, M. (2010). The predominance of procedural knowledge in fractions. In I. Sparrow, B. Kissane, \& C. Hurst, Shaping the future of mathematics education MERGA33 (pp. 185-192). Fremantle: Merga Inc.

Ghazali, N. H., \& Zakaria, E. (2011). Students' procedural and conceptual understanding of mathematics. Australian journal of basic and applied sciences , 5(7), 684-691.

Haapasalo, L., \& Kadijevich, D. (2000). Two types of mathematical knowledge and their relation. Journal for mathematics education., 21(2), 139-157. https://doi.org/10.1007/bf03338914

Hardin, L. E. (2002). Educational strategies. Problem solving concepts and theories. Journal of veterinary medical education, 30(3), 227-230.

Hiebert, J. (2013). Conceptual and procedural knowledge: The case of mathematics. Routledge. https://doi.org/10.4324/9780203063538

Hiebert, J., \& Lefevre, P. (1986). Conceptual and procedural knowledge in mathematics: An introductory analysis. In J. Hiebert, Conceptual and procedural knowledge: The case of mathematics (pp. 1-27). Hillsdale, NJ: Erlbaum.

Ho, T. M. (2020). Measuring conceptual understanding, procedural fluency and integrating procedural and conceptual knowledge in mathematical problem solving. International journal of scientific research and management, 8(5), 1334-1350. https://doi.org/10.18535/ijsrm/v8i05.el02

Hodgen, J., \& Jones, I. (2013). Measuring conceptual understanding: The case of fractions . Proceedings of the 37th conference of the international group for the Psychology of Mathematics Education. Kiel, Germany: PME.

Huang, T., Liu, S., \& Lin, C. (2007). Preservice teachers' mathematical knowledge of fractions. Research in higher education journal, 1-8.

Hurrell, D. P. (2021). Conceptual knowledge OR Procedural knowledge OR Conceptual knowledge AND Procedural knowledge:Why the conjunction is important for teachers. Australian journal of teacher education, 46(2), 57-71. https://doi.org/10.14221/ajte.2021v46n2.4

Kadijevich, D. M. (2018). Relating procedural and conceptual knowledge. Teaching of mathematics, 21(1), 15-18.

Khashan, K. H. (2014). Conceptual and procedural knowledge of rational number for Riyadh elementary school teachers. Journal of education and human development, 3(4), 181-197. https://doi.org/10.15640/iehd.v3n4a17

Kieran, C. (2013). The false dichotomy in mathematics education between conceptual understanding and procedural skills: An example from algebra. In K. Leatham, Vital directions for mathematics education research. New York: Springer. https://doi.org/10.1007/978-1-4614-6977-3

Lenz, K., \& Wittmann, G. (2021). Individual differences in conceptual and procedural fraction knowledge: What makes the difference and what does it look like? International electronic journal of mathematics education, 16(1), em0615. https://doi.org/10.29333/iejme/9282

Long, C. (2005). Mathematics concepts in teaching: Procedural and conceptual knowledge. Pythagoras(62), 59-65. https://doi.org/10.4102/pythagoras.v0i62.115 
Mabilangan, R. A., Limjap, A. A., \& Belecina, R. R. (2011). Problem solving strategies of high school students on non-routine problems: A case study. A journal of basic education., 5, 23-46.

Maulina, R., Zubainur, C. M., \& Bahrun. (2020). Conceptual and procedural knowledge of junior high school students through realistic mathematics education (RME) approach. Journal of Physics: Conference series 1460 012017, 1-6. https://doi.org/10.1088/17426596/1460/1/012017

Nahdi, D. S., \& Jatsunda, M. G. (2020). Conceptual understanding and procedural knowledge: A case study on learning mathematics of fractional material in elementary school. Journal of Physics: Conference series 1477 042037, 1-5. https://doi.org/10.1088/1742-6596/1477/4/042037

Ndemo, Z., \& Ndemo, O. (2018). Secondary school students' errors and misconceptions in learning algebra. Journal of education and learning, 12(4), 690-701. https://doi.org/10.11591/edulearn.v12i4.9556

Oregon department of Education. (1991). Oregon Mathematics problem solving rubrics. Retrieved May 29, 2021, from https://web.njit.edu/ ronkowit/presentations/ rubrics/samples/math probsolv chicago.pdf

Rittle-Johnson, B., \& Alibali, M. (1999). Conceptual and procedural knowledge of mathematics: Does one lead to the other? Journal of educational psychology, 91(1), 175-189. https://doi.org/10.1037/0022-0663.91.1.175

Rittle-Johnson, B., \& Schneider, M. (2012). Developing conceptual and procedural knowledge of mathematics. In R. Cohen Kadosh, \& A. Dowker, Oxford handbook of numerical cognition. Oxford: University press.

Rittle-Johnson, B., Siegler, R. S., \& Alibali, M. W. (2001). Developing conceptual understanding and procedural skill in mathematics: An iterative process. Journal of educational psychology, 93(2), 346-362. https://doi.org/10.1037//0022$\underline{0663.93 .2 .346}$

Schneider, M., \& Stern, E. (2010). The developmental relations between conceptual and procedural knowledge: A multimethod approach. Developmental Psychology, 46(1), 178-192. https://doi.org/10.1037/a0016701

Schneider, M., Rittle-Johnson, B., \& Star, J. R. (2011). Relations among conceptual knowledge, procedural knowledge, and procedural flexibility in two samples differing in prior knowledge. Developmental psychology, 47(6), 1525-1538. https://doi.org/10.1037/a0024997

Schwartz, J. E. (2008). Elementary mathematics pedagogical content knowledge: Powerful ideas for teachers. Virginia: Allyn and Bacon.

Simpson, A., \& Zakaria, N. (2004). Making the connection: Procedural and conceptual students' use of linking words in solving problems. . Proceedings of the 28th conference of the international group for the psychology of mathematics education, 4 , pp. 201-208.

Star, J. R. (2005). "Re-conceptualising" procedural knowledge. Journal for research in mathematics education, 36(5), 404-411.

Star, J. R. (2007). Foregrounding procedural knowledge. Journal for research in mathematics education, 38(2), 132-135.

Star, J. R., Caronongan, P., Foegen, A., Furgeson, J., Keating, B., Larson, M. R., Lyskawa, J., McCallum, W. G., Porath, J., \& Zbiek, R. M. (2015). Teaching strategies for improving algebra knowledge in middle and high school students (NCEE 2014-4333). Washington, DC: National Center for Education Evaluation and Regional Assistance 
(NCEE), Institute of Education Sciences, U.S. Department of Education. Retrieved from http://whatworks.ed.gov

Star, J. R., \& Seifert, C. (2006). The development of flexible procedural knowledge in equation solving. Contemporary educational psychology, 31(3), 280-300. https://doi.org/10.1016/i.cedpsych.2005.08.001

Star, J. R., \& Stylianides, G. J. (2013). Procedural and conceptual knowledge: Exploring the gap between knowledge type and knowledge quality. Canadian journal of science, mathematics and technology education, 13(2), 169-181. https://doi.org/10.1080/14926156.2013.784828

Syam, A. S. (2019). How students understand the linear equation and inequalities (Factual, Conceptual, Procedural Knowledge). Proceedings of the 1st Vocational Education International Conference (VEIC 2019).379, pp. 119-125. Amsterdam: Atlantis Press SARL. https://doi.org/10.2991/assehr.k.191217.020

Tesfayi, A., Arefayne, N., \& Micael, K. (2020). Early Grade Children Procedural and Conceptual Knowledge in Number Pattern Concept at Halaba. Developing Country Studies, 10(12), 1-8. https://doi.org/10.7176/DCS/10-12-01

Tularam, G. A., \& Hulsman, K. (2013). A study of first year tertiary students' mathematical knowledge- conceptual and procedural knowledge, logical thinking and creativity. $\begin{array}{llll}\text { Journal of mathematics and statistics, 9(3), 219-237. } & \text {. }\end{array}$ https://doi.org/10.3844/jmssp.2013.219.237

Zakaria, E., \& Zaini, N. (2009). Conceptual and procedural knowledge of rational numbers in trainee teachers. European journal of social sciences, 9(2), 202-217. 